If anyone reading this would like to get involved I would be delighted to hear from them.

JUNE MCKERROW

Director

The Mental Health Foundation

37 Mortimer Street

London WIN $7 R J$

\section{Realising a vision}

\section{DeAr Sirs}

I read with interest Julian Candy's paper 'Realising a Vision: Psychiatry in Aylesbury 1983-91' (Psychiatric Bulletin, August 1993, 17, 458-461) and having worked in Aylesbury throughout those years, both centrally and in the Buckingham Mental Health Service (BMHS) I would like to respond.

One feature of the BMHS is its flexibility and compromise in patient care, qualities not always afforded by many teams. It is interesting to note the title, as the real vision realised throughout those years in Aylesbury Vale was the BMHS - realised on transition from project to service.

Many people recognise and thank Ian Falloon for his progressive ideas on community care and his tenacity in "sticking it out", despite not having the wholehearted support from more traditional colleagues. He has always recognised the significant contribution made by clinicians in allied professions in bringing change and improvements in patient care. He would recognise that innovative services or traditional services do not succeed or fail on the contribution of one individual or profession. Medical commitment to change is not more or less important than any other profession's commitment. Is it not time that psychiatrists developed a sense of proportion about their contribution?

CAROLINE BIRCH
Senior Nurse (Community Mental Health)
Buckingham Mental
Health Service
Buckingham MK18 INV

\section{Reply}

DeAR SIRS

Undoubtedly the BMHS represents the realisation of a vision, and like Caroline Birch I recognise the tenacity and commitment of its founder. My impression is that its capacity for positive flexibility and compromise has grown as it has matured with time (though I cannot speak directly about the last 18 months). However, we in the rest of Aylesbury Vale had a vision too, and not that of one man or one profession; I remember in the early days the chief nurse, the manager and myself thrashing out our 'vision' of a comprehensive service, and discuss- ing then how to share it with and enrich it from the other professions.

Of course, for success commitment from all professions is needed. Writing as I was principally for psychiatrists, I wanted to stress the dangers for them and for the service of remaining aloof from or indifferent to developing CMHTs, something which in other parts the country has had destructive results. Equally, CPNs or social workers or psychologists or OTs who want to remain or become independent practitioners cannot constructively remain in a service which is set on the path of close interprofessional collaboration. I remain convinced though that committed medical input, which indeed the BMHS has enjoyed throughout, is central and essential in any effective service.

\section{Shamrock Way \\ Hythe Marina Village \\ Southampton SO46DY}

\section{Administration of ECT by GP trainees}

\section{DEAR SIRS}

I share Littlejohn's concern (Psychiatric Bulletin, August 1993, 17, 497-498) that GP trainees should not be excluded from ECT rotas. I would argue that it is relevant and useful for such trainees to gain firsthand experience of the technique. ECT continues to cause public concern and, not surprisingly, relatives of depressed patients undergoing ECT frequently visit their own doctor to express worries, and ask about this relative's condition and its treatment. What could be more reassuring than for their own trusted and experienced family doctor to be able to say "when I was training to be a GP, I spent six months in psychiatry during which time I administered ECT myself many times. It is a safe and effective procedure".

Mental illness and its treatment still carry a stigma, and nowhere is this more pronounced than with ECT. Surely we need to ensure that as many nonpsychiatrists as possible gain first-hand experience of the procedure? With correct supervision, the administration of ECT is not so difficult that it cannot be done safely by any doctor. We must avoid adding to the sinister mystique of ECT by hiding it away from branches of our own medical profession. A large number of GP trainees pass through psychiatry and provide a pool of future trained doctors able to give a balanced argument in favour of ECT. This ensures that it is not just psychiatrists who can confirm the benefit of the treatment. ECT can ill afford to lose such valuable advocates.

Friarage Hospital

G. E. P. VINCENTI

Northallerton, North Yorkshire

DL6 IJG 